\title{
Bolivarianismos de papel
}

\author{
por \\ Frédérique Langue ${ }^{1}$ \\ IHTP-CNRS
}

Este ensayo reconsidera no tanto las modalidades del culto a Bolivar en su vertiente oficialista sino la manera como se convirtió en teoría para el pensamiento y la acción política en el tiempo largo. Con este fin, insistiremos en la problemática de las relaciones civico-militares, piedra de toque del proyecto bolivariano de Hugo Chávez. Asimismo contemplaremos las representaciones ligadas al ideario bolivariano tanto dentro como fuera del mundo académico y del gremio de los historiadores, incluyendo las recientes y tendenciosas reescrituras memoriales del tiempo presente venezolano.

Palabras Clave: Venezuela; bolivarianismo; memoria; Hugo Chávez; pretorianismo; revolución; independencia.

Cómo CitAR este artículo / Citation: Langue, Frédérique, "Bolivarianismos de papel", Revista de Indias, LXXVII/270 (Madrid, 2017): 357-378, doi:10.3989/revindias.2017.011.

En uno de los primeros estudios críticos dedicados al Libertador y a las relaciones civiles-militares, Domingo Irwin y Luis Alberto Buttó, reconocidos especialistas de las relaciones civiles-militares venezolanas, iniciaron su reflexión haciendo referencia a un postulado de M. Deas. Este consideró que el bolivarianismo no era sino «una ideología sin contenido», circunstancia que también tuvimos la oportunidad de comprobar analizando el ideario y los discursos de Hugo Chávez, aunque con la siguiente salvedad: en el chavismo confluyeron en realidad varias influencias y corrientes de ideas ${ }^{2}$. Si bien du-

\footnotetext{
1 frederique.langue@ihtp.cnrs.fr flangue@univ-paris8.fr ORCID iD: http://orcid.org/ 0000-0002-0464-1388.

2 “Malcolm Deas", entrevista por Alfredo Meza, El Nacional (Caracas), 16/01/2005, citado por Irwin y Buttó, 2006a: 82-87. Langue, 2002: 62-101.
} 
rante los primeros años del gobierno de Hugo Chávez (1999-2013) se subrayó hasta la saciedad que el chavismo no era una ideología en el sentido epistemológico del término -o sea en la perspectiva marxista y especialmente althusseriana- sino un conjunto de influencias y lecturas de lo más diversas, ampliamente señaladas por su líder en su emisión dominical Aló Presidente, la paulatina radicalización de la «Revolución bolivariana» hacia el Socialismo del siglo XXI arrojó datos distintos.

Desde el advenimiento de $\mathrm{H}$. Chávez y especialmente desde el intento de golpe de Estado de 2002 en su contra -los llamados «sucesos de abril»-, presenciamos en efecto una radicalización del «proceso» junto a una mayor e inédita arremetida de la historia oficial, siguiendo pautas algo divergentes respecto al culto a Bolívar tal como lo habían ideado y celebrado anteriormente los gobernantes criollos a través de la consabida «historia patria». La escritura de la historia nacional se desenvuelve en adelante en un contexto globalizado y en gran parte ideologizado por el protagonismo cubano in situ. Destaca en este aspecto el mayor uso de los nuevos medios de comunicación e información en una contienda que hasta fue calificada de «guerra de cuarta generación»o «asimétrica», fundada precisamente en una guerra informativa, ciberguerra o guerra digital. Reconsiderar los antecedentes del movimiento bolivariano permite en este sentido delinear las modalidades de esta evolución sui generis ligada a la historia de las relaciones civiles-militares y por lo tanto al pretorianismo criollo más que al connotado militarismo preciado de los analistas externos ${ }^{3}$.

La propaganda oficialista, dentro y fuera de las fronteras nacionales, fomentó una interpretación peculiar del culto al héroe fundador de la nación y de la revolución de Independencia (1810-1821) -el «bolivarismo» propiamente dicho- y al Libertador del siglo XX/XXI a la par que integró elementos exógenos que poco tienen que ver con la idiosincrasia criolla sino con el espejismo bien conocido de «la luna y del caudillo», y más cuando de los medios de comunicación y de la (seudo) intelectualidad afín se trata. Usos instrumentalizados y hasta desvirtuados del pasado, coyuntura hemisférica del siglo XXI, ideologías mundial y pragmáticamente recompuestas, conmemoraciones y reescrituras bicentenarias conforman un escenario donde la esperanzada «revolución» y su teleología -el «divino Bolívar» ejemplificado por

3 Elías Pino Iturrieta, "La historia oficial”, El Universal (Caracas, 27/10/2003) http:// www.eluniversal.com/2003/10/27/opi_art_27490B.shtml. Langue, 2016a. Irwin, 2000a. Consideramos aquí el período formativo del movimiento bolivariano así como el período de gobierno de Hugo Chávez (1999-2013), no la presidencia de su sucesor el civil Nicolás Maduro, sin embargo más proclive a abocarse a opciones militaristas. 
Elías Pino- se subsumen en unas creencias de cuño mágico-religioso (Cf. Michaelle Asencio) en pro de un liderazgo carismático ${ }^{4}$. De «comandante», Chávez pasa a ser "comandante supremo» y «gigante» luego de su muerte, «comandante galáctico», "padre» que le habla a su sucesor en una iglesia por medio de un pajarito etc. Al llegar a los cielos ( sic), se encuentra con los «buenos» de la historia -sus propios héroes- como aparece a todas luces en un dibujo animado promovido por los canales oficiales de televisión del Estado: Salvador Allende, el Che, el cacique Guaicaipuro, el cantautor Alí Primera, Evita Perón etc 5 . Ambas, tanto la revolución como la teleología que conlleva, estrechamente vinculada con la «historia insurgente» fomentada por el muy oficial Centro Nacional de Historia (2007), tienden sin embargo a confortar una cultura de guerra asentada en el lema de la "segunda Independencia», en contra del «segundo imperio» (ya no España sino Estados Unidos). Así contribuyen en crear un régimen emocional que se le sobrepone al régimen de historicidad manejado hasta ahora por los historiadores de oficio, en su gran mayoría adversos al régimen ${ }^{6}$.

De tal forma que la «guerra de las memorias» se ha convertido en uno de los aspectos más notables de la historia de un tiempo presente venezolano heredero del culto a Bolívar, expresivo de un personalismo político característico de las prácticas políticas criollas desde el siglo XIX desde el mismo Bolívar (Cf. en 1828 el cesarismo presente en la dictadura comisoria que le confiere al Libertador el poder absoluto, y antes, el Manifiesto de Cartagena en 1812 o la Carta de Jamaica de 1815) y en cuanto mito fundador de una nación ahora duradera e irremediablemente divida. En este sentido, no fue baladí la visionaria interpretación de Carlos Rangel, quien desde 1976 y con motivo de la publicación de su ensayo Del buen Salvaje al Buen Revolucionario, formuló su «diagnóstico de Bolívar», destacando el papel del caudillismo y por lo tanto «partido militar» en la historia de su país. En la línea de la «leyenda negra», C. Rangel identifica en el mito del «buen salvaje» el anclaje de otro mito, de otro liderazgo y de otra tiranía, con un «buen revolucionario» llamado a salvar a Latinoamérica, así del imperialismo ${ }^{7}$.

4 Pino Iturrieta, 2003. Ascensio, 2012.

5 https://www.youtube.com/watch?v=39D5IU7o8KI publicado por AFP, 29 de marzo de 2013 y en Univisión: 'Hugo Chávez que estás en los cielos', homenaje a Chávez - Despierta América, 21/6/2013 https://www.youtube.com/watch? v=g17TMx5mNy0.

${ }^{6}$ Langue, 2011.

7 Sobre los orígenes del personalismo político en Venezuela, véase Pino Iturrrieta, 2007. José Ignacio Hernández, "Del buen salvaje al buen revolucionario, cuarenta años después", Prodavinci (Caracas, 31/10/2016) http://prodavinci.com/blogs/del-buen-salvaje-al-buen-revolucionario-cuarenta-anos-despues-por-jose-ignacio-hernandez/. 
De la Revolución de IndePendencia al SAMÁN DE GÜERE Y AL «Divino BOLÍVAR»: UNA MIRADA REGRESIVA

El «culto a Bolívar» se origina en la Revolución de Independencia de Venezuela (1810-1821) y en la gesta guerrera del héroe epónimo y Libertador Simón Bolívar, representante de la aristocracia criolla blanca de los «mantuanos». Pese al fracaso final de la Gran Colombia y luego de una contienda considerada como una de las más violentas del continente, el culto cívico dio paso al establecimiento de una verdadera «religión republicana» cuya dimensión consensuada corrió parejas con la formación de la nación venezolana. Este culto «por y para el pueblo», de acuerdo con la caracterización de historiador y diplomático Germán Carrera Damas, se oficializó a fines del siglo XIX durante el gobierno del «Ilustre Americano» y positivista Antonio Guzmán Blanco (durante los llamados septenio, quinquenio y bienio en el período que va de 1870 a 1788), abriendo paso a la escritura de una historia oficial firmemente arraigada en el culto heroico ${ }^{8}$.

Más allá de la tradicional «historiografía patria» y de los usos del pasado propios de los mandatarios criollos, el culto bolivariano alcanzó una etapa decisiva con la llegada de Hugo Chávez a la Presidencia de la República (1999) y se radicalizó sobremanera a lo largo de su mandato. Apologeta de una «segunda Independencia», Chávez se convierte en el «Bolívar del siglo $\mathrm{XX} / \mathrm{XXI}$ », en el mesías y salvador del continente, postura que asumiría sin rodeos en su discurso de 2006 ante la ONU o en foros alter mundialistas, en un contexto continental que fue primero de auge de las izquierdas latinoamericanas. En estas condiciones, la historia ampliamente interpretada en los medios de comunicación oficialistas y reformulada incluso por medio de la propaganda visual [cine incluido para mencionar tan sólo el largo metraje de Diego Rísquez, Miranda regresa (2006), y la última y polémica película de Luis Alberto Lamata, Libertador (2013)] se hace «sierva», según la fórmula acuñada por Lucien Febvre, no hace sino respaldar un propósito político en un contexto conmemorativo de lo más favorable ya que el final de su presidencia coincidió con las conmemoraciones del Bicentenario de las Independencias iberoamericanas?.

8 Carrera Damas, 1989.

9 Inés Quintero, “En torno a la película 'Libertador': Los héroes mueren de pie”, Prodavinci (Caracas, 4/8/2014), http://prodavinci.com/blogs/en-torno-a-la-pelicula-libertador-losheroes-mueren-de-pie-por-ines-quintero/vinci. Tomás Straka, "Bolívar, dos películas, ¿una epopeya?", Prodavinci (Caracas, 28/7/2014), http://prodavinci.com/2014/07/28/artes/bolivardos-peliculas-una-epopeya-por-tomas-straka/print/. Langue, 2009. 
Cabe recordar sin embargo que el éxito inicialmente granjeado por el carismático «comandante» descansó en una exigencia de justicia social -de ahí la referencia a la democracia participativa durante la campaña electoral para las elecciones presidenciales de 1998 durante los primeros años de gobiernoen contraposición a la democracia representativa instaurada a raíz de la caída de la dictadura o mejor dicho de la «dictablanda» de Marco Pérez Jiménez y del Pacto de Punto Fijo (1958), punto de partida del bipartidismo criollo. Lo mismo que la gesta bolivariana retoma hechos y discursos del Libertador, el itinerario simbólico de Hugo Chávez incluye fechas claves para la elaboración de la figura del «Bolívar del siglo XX/XXI». Las revueltas populares y antiliberales de febrero de 1989, más conocidas como el «Caracazo», que desembocaron en la toma de conciencia de los jóvenes oficiales, entre ellos Hugo Chávez, el fallido aunque muy mediatizado (el «por ahora») golpe de Estado del 4 de febrero de 1992 protagonizado por el entonces teniente coronel o «rebelión de los ángeles» de acuerdo con el libro de una periodista ex guerrillera, ex comunista y amiga del «comandante» pasada luego a una postura mucho más crítica (en su nuevo libro En nombre de los pobres, 2015), son fechas clave al respecto, y, en todo caso, aconteceres que no dejan de confortar la popularidad del «mago de las emociones» ${ }^{10}$. La aparente ruptura de abril 2002 en términos de radicalización de una revolución que no vacilará en proclamarse «armada» sienta las bases de un modelo estatal más autoritario que culminaría a los pocos años con la creación del PSUV en 2008 (Partido Socialista Unificado de Venezuela, pese a la oposición de varios aliados como el Partido Comunista (PCV), el Movimiento Tupamaro o Patria para Todos). Desembocará asimismo en la proclamación del controvertido «Socialismo del siglo XXI», promovido por el sociólogo Heinz Dieterich con una fachada de «democracia electoral». En adelante, la Revolución adopta un funcionamiento binario que no deja de recordar el modelo cubano: uno está a favor o uno está en contra, no hay término medio ${ }^{11}$.

A partir de ese momento, la propaganda oficialista y la historia oficial incorporan clara y abiertamente a Hugo Chávez en la gesta de los Libertadores del continente latinoamericano y en una retórica anti-imperialista: el Bolívar de los siglos XX y XXI es el «nuevo constructor de la Patria Grande» -sueño inconcluso de Bolívar-y artesano del «destino superior de los pueblos latinoamericanos», de acuerdo con una larga entrevista que le concedió a uno

10 Zago, 1998. Entrevista a A. Zago por Paulo Lazo, Diario Las Américas, 26/08/2015: "Periodista que admiró el chavismo denuncia abusos en su país", http://www.diariolasamericas. com/periodista-que-admiro-el-chavismo-denuncia-abusos-su-pais-n3299874. Uzcátegui, 1999.

11 Ramos Jiménez, 2009. Langue, 2015. 
de sus ideólogos, el analista alemán-mexicano Heinz Dieterich, otrora turiferario de las izquierdas revolucionarias del continente, ahora pasado también a una postura crítica de lo más radical, incluso desde el el sitio chavista Aporrea $^{12}$. Para entender mejor la manera como el bolivarianismo cundió en Venezuela en su forma quizás más autoritaria y estrechamente vinculado al sector militar, pese a las proclamas propagandistas del régimen y a la sesgada reescritura «revolucionaria» de la vida del mismo Libertador, resulta fundamental reconsiderar los fundamentos del imaginario político nacional en el siglo XX, siguiendo también el enfoque regresivo señalado anteriormente. Al igual que los partidos que lo sustentan y que inspira a la vez, el imaginario político moderno se remonta a la primera etapa democrática del siglo $\mathrm{XX}$, osea los años 1940, con la fundación de los partidos Acción Democrática (AD, social demócrata, 1941) y COPEI (social cristiano, 1946) y encierra unas cuantas paradojas en lo que a representación política se refiere. A diferencia de otros partidos populistas, como sucedió en la Argentina de Juan Vicente Perón o en el Brasil de Vargas, AD cuenta en efecto entre sus fundadores a unos ex comunistas exiliados, entre ellos a quien fuera el «padre de la democracia» y mayor teórico del partido, Rómulo Betancourt, sigilosamente pasado por alto por los exegetas de la República Bolivariana en su manoseada reescritura de la historia nacional y empeñado olvido de la «Cuarta» (Repú(blica) $)^{13}$.

La segunda paradoja, quizás la que mejor definiría al pretorianismo y a la institucionalidad criolla en el tiempo largo, incluso en su vertiente democrática, es el hecho de que este partido llegó al poder y desplazó a la élite establecida durante el gobierno del «tirano liberal» Juan Vicente Gómez (19081935), por medio de un golpe de Estado: la llamada «revolución de octubre» del 18 de octubre de 1945, que, en realidad, no fue una revolución sino un pronunciamiento militar clásico pese a la constitución de una «Junta Revolucionaria de Gobierno» al siguiente día. R. Betancourt consideró en esa oportunidad que «el gobierno de facto nació de un golpe de Estado clásico y no de una bravía insurgencia popular» y atribuyó el hecho al «descontento del ejército». Tal fue el punto de partida de la «simbiosis civil-militar» y «político-militar» tal como la ejemplificó Domingo Irwin, simbiosis que marcaría

12 Dieterich, 2004. Heinz Dieterich, "El Gobierno militar de Venezuela y la sombra de Allende", Aporrea (Caracas, 17/07/2016), https://www.aporrea.org/ideologia/a231017.html. Heinz Dieterich, "En Venezuela hay una dictadura encabezada por una tropa de rasputines", Contrapunto.com, 23/05/2017, http://contrapunto.com/noticia/dieterich-en-venezuela-hayuna-dictadura-encabezada-por-una-tropa-de-rasputines-115370/.

13 Dávila, 1992. Langue, 2015. 
sobremanera el período que va del derrocamiento del presidente Rómulo Gallegos (1958) hasta la dictadura de M. Pérez Jiménez (1948-1958), la caída de éste a raíz de otra conspiración, otro golpe de Estado protagonizado por una junta cívico-militar presidida por el vice-almirante Wolfgang Larrazábal el 23 de enero de 1958, y la firma del pacto de Punto Fijo entre los partidos $\mathrm{AD}, \mathrm{COPEI}$ y URD el 31 de octubre del mismo año. Así se estableció una democracia representativa que iba a perdurar durante cuatro décadas, y por eso mismo, una democracia ejemplar a nivel de un continente dominado por regímenes autoritarios si no dictaduras militares. Es el denominado «excepcionalismo» venezolano, una democracia exenta de violencia militar, marcada por la bonanza petrolera (la «Venezuela saudita») y el consenso de las élites o «sistema populista de conciliación nacional», que toca a su fin con la llegada de Hugo Chávez a la presidencia de la República. Fue este consenso que permitió acabar con la lucha armada (guerrillas del Movimiento de Izquierda Revolucionaria (MIR) y del Partido Comunista) en los años 1960 y especialmente con las sublevaciones militares del año 1962. En este sentido, el pretorianismo remite a una influencia abusiva del sector militar, o a la utilización por éste de la fuerza, tanto en lo simbólico como en la realidad, sin por eso dar al traste con el sin embargo malogrado control civil (o subordinación de las fuerzas armadas al control civil) estrechamente vinculado con el estado de las instituciones democráticas ${ }^{14}$.

\section{EL BOLIVARIANISMO ENTRE CONSPIRACIONES Y LITURGIAS}

De acuerdo con D. Irwin, el pretorianismo como tendencia conspirativa seguiría existiendo en un estado latente a lo largo del siglo XX, pese a la modernización del ejército en los años treinta, durante el gomecismo. De tal forma que los intentos golpistas del año 1992, incluyendo la intentona protagonizada por el mismo Chávez, y el golpe urdido en su contra en abril de 2002, no serían sino la «expresión de un pretorianismo recurrente del siglo XX». El término militarismo en cambio, un término mucho más connotado y de uso más reciente, remite a una situación política en la cual el sector militar tiende a invadir y por lo tanto a controlar la sociedad (civil) en su conjunto, sendas consideraciones que no podemos pasar por alto a la hora de

14 Coppedge, 1994; 2005. Sobre Pérez Jiménez, véase Alarico Gómez, 2007 y Caballero, 2004: 226 (donde cita a R. Betancourt). Castillo, 2013. Irwin, 2000b: 190. Irwin y Langue, 2004. 
definir el mandato del sucesor de Chávez, el presidente N. Maduro ${ }^{15}$. En esta tendencia pretoriana hay que ubicar los orígenes el movimiento bolivariano (Ejército Bolivariano Revolucionario y luego Movimiento Bolivariano Revolucionario 200), logia militar clandestina fundada por Hugo Chávez junto con Jesús Urdaneta, Raúl Isaías Baduel, Felipe Antonio Acosta Carlez, con motivo del bicentenario del nacimiento del Libertador Simón Bolívar, un 17 de diciembre de 1982, con juramento «bolivariano» similar al realizado por el Libertador en el Monte Sacro, en este caso bajo el samán de Güere (en el Estado Aragua). De esta misma tendencia se derivaron otras logias militares como R-83 (Revolución 83) y ARMA (Alianza Revolucionaria de Militares Activos), liderada por el teniente-coronel William Izarra, -compañero de Hugo Chávez-. Ya tuvimos la oportunidad de señalar la importancia de las revueltas populares de febrero de 1989 y la represión de las mismas por el gobierno de «CAP» en la toma de conciencia de los jóvenes militares, en un contexto de crisis política y financiera, de corrupción -circunstancia única en la historia política del país, el presidente Carlos Andrés Pérez (CAP) fue destituido de su segundo mandato en 1993- y por lo tanto de desconfianza respecto a los partidos tradicionales. A raíz del fallido golpe de Estado, la «rebelión de los ángeles» (1992), el movimiento bolivariano fue cambiando de estrategia con vistas a la llegada al poder ${ }^{16}$.

Fue por medio de elecciones, ya no de un alzamiento militar (a diferencia de guerrilleros radicales como Douglas Bravo, quien nunca aceptó la derrota de la guerrilla), en un movimiento que se relacionó con representantes de una izquierda radical y fue incorporando en adelante a los civiles, el Movimiento Va República (1997), como el bolivarianismo en su expresión cívico-militar llegó a la Presidencia de la República (diciembre de 1998). La opción civilista seguirá vigente hasta la fusión del MVR en el PSUV. A partir de este momento predominaría la figura del «ciudadano-soldado», la «defensa popular integral», y la «fusión civil-militar» de los textos fundadores del movimiento bolivariano: el proyecto bolivariano fundado en el «árbol de las tres raíces» (el Libertador Simón Bolívar, el educador Simón Rodríguez y el «general del pueblo soberano» Ezequiel Zamora) pasó a ser de forma definitiva el «proceso» de alcance mucho más globalizado y en todo caso «hemisférico» ejemplificado en el ALBA (Alianza Bolivariana para las Américas, fundada en La Habana en 2004). Hay que mencionar en este aspecto el influ-

15 Irwin, 2000b: 194; 2001.

16 "Destitución de CAP es el único antecedente de «Juicio Político»", Tal Cual, 12-112016, http://www.talcualdigital.com/Nota/134588/destitucion-de-cap-es-el-unico-antecedente-de-juicio-politico. Garrido, 2000. Langue, 2002: 55. Blanco Muñoz, 1998; 2006. 
jo de otros ideólogos que vinieron a reforzar el discurso anti-imperialista de Chávez: el sociólogo argentino Norberto Ceresole, teórico de la relación caudillo-ejército-pueblo y consejero de Chávez, o, en menor medida, el politólogo español Jorge Verstrynge, ex secretario de Alianza Popular antes de convertirse en comunista y teórico de la «guerra asimétrica»). Ambos promueven el resurgimiento del sector militar convertido en árbitro político en la línea trazada por la Constitución Bolivariana de 1999 y luego por las distintas leyes orgánicas de las Fuerzas Armadas, que refuerzan su protagonismo mucho más allá de los temas de seguridad y defensa ${ }^{17}$.

El nuevo discurso bolivariano es producto por lo tanto de un imaginario de larga duración, resultante de la omnipresencia de un mito bolivariano arraigado en las prácticas políticas desde la Revolución de Independencia. La «religión cívica» tal como la señalamos anteriormente se establece durante el régimen positivista de Guzmán Blanco, «Supremo Sacerdote» del culto según E. Pino (1870-1888). Ahora bien, es en 1842, cuando las cenizas del héroe fueron repatriadas a Caracas (Bolívar murió en Santa Marta en 1830), repatriación debidamente celebrada por el fundador del Partido Liberal Antonio Leocadio Guzmán en El Venezolano (29/11/1842), que se inicia verdaderamente el culto desde la cúspide del Estado y que se crean «lugares de memoria» al efecto (plazas, lugares de ceremonias diversas). Cada 28 de octubre, día de San Simón, se realizan fiestas conmemorativas, así como por ejemplo la inauguración de la estatua ecuestre de Bolivar (1874) o la apoteosis luctuosa de 1976, cuando se trasladan los restos del Libertador desde la Catedral hasta el Panteón Nacional de reciente creación. Portador de reconciliación nacional y piedra angular de la nacionalidad, Simón Bolívar se convierte en la representación de las virtudes, la encarnación de los principios republicanos, igualdad incluida, como lo expresó Fermín Toro en su Descripción de los honores fúnebres (1842). Dentro del culto fundacional, un monumento desempeña un papel especial: el Panteón nacional edificado sobre la estructura de la antigua iglesia caraqueña de la Santísima Trinidad e inaugurado por Guzmán Blanco en 1875. Allí descansan los restos de personajes ilustres, entre ellos el Libertador colocado en el lugar de la Divina Majestad -el sarcófago del «Padre de la Patria» sustituyó al altar mayor-, en un lugar integrado hoy en día en las celebraciones oficiales junto a otro mausoleo más moderno pero que nunca llegó a funcionar como tal. Los restos de H. Chávez siguen reposando en efecto en el antiguo cuartel de la Montaña, en las cerca2015 .

17 Irwin y Langue, 2004. Ceresole, 2000. Irwin, 2000a. Irwin y Buttó, 2006b. Langue, 
nías del barrio popular el 23 de enero, así nombrado en referencia a la caída de Pérez Jiménez.

Fue durante el guzmanato cuando se inició la liturgia cívica con su calendario, sus desfiles y exhibiciones de reliquias y estatuas del héroe convertido en «Dios de la Nación frente al Dios del Universo». Ahora bien, no fue sino a raíz de la «Revolución de octubre» de 1945 cuando se forjó el imaginario redentor y el «patrimonio moral» que $\mathrm{H}$. Chávez llevó al paroxismo -quería «salvar al mundo» de acuerdo con un discurso de 2006 pronunciado en la ONU- y plasmó en la nueva Constitución de 1999 que cambió la denominación del país, devenida en República Bolivariana de Venezuela. Recordemos también que no fueron pocas las apariciones del nuevo salvador del continente con el librito azul en una mano (la Constitución bolivariana de 1999) y un crucifijo en la otra, expresiva de esta tendencia a la religiosidad criolla ejemplificada por Michaelle Ascensio. De hecho, el Bolívar del siglo XX/XXI también se incluiría en los altares populares dedicados al culto a la «diosa» María Lionza, donde el Libertador está a la cabeza de la llamada Corte Libertadora, transformado en «paladín de los necesitados» junto con otros guerreros ilustres de la época de la Independencia o representantes del mundo mestizo o indígena como el cacique Guacaipuro ${ }^{18}$.

\section{REgRESANDO A LÓPEZ CONTRERAS: PRETORIANISMO Y BOLIVARIANISMOS}

El bolivarianismo como tal, dicho de otra forma como «concepto público coherente», doctrina y hasta «norma de gobierno» (D. Irwin, L.A. Buttó) se remonta al gobierno del General Eleazar López Contreras, presidente de la República de 1936 a 1941 y asociado a la creación de un moderno ejército institucional venezolano, en ruptura con la era de los caudillos y portador de una autoridad moral. La pretendida doctrina oficial del régimen buscaría contrarrestar la manifiesta influencia pretoriana tal como la había encarnado la «tiranía pretoriana» de Juan Vicente Gómez (1908-1935), de quien se considera sin embargo que posibilitó la entrada de Venezuela en la modernidad económica, institucional, y militar. El bolivarianismo así entendido no es precisamente el bolivarianismo de izquierdas reivindicado por el chavismo ya que el ideal forjado por el General Eleazar López Contreras apuntaba a luchar contra el «bolchevismo» o sea la amenaza comunista, considerada además anti-patriótica. Contemplaba, apoyándose en el nuevo profesionalismo militar tal como lo describiría S. Huntington, la posibilidad e incluso el derecho de

18 Pino Iturrieta, 2003: 25-27, 44 y ss. y 170 y ss. Quintero, 2012. Ascensio, 2012. 
la oficialidad de intervenir en los asuntos del país, situación que se observó de igual manera en la segunda mitad del siglo XX latinoamericano. De hecho, el bolivarianismo se caracteriza por su pluralidad ideológica. Se declina en la vida política venezolana en dos versiones distintas e incluso contradictorias: ésta última, fomentada por López Contreras, más bien de derecha y anti socialista, y otra, surgida en las postrimerías del siglo XX, de izquierda y socialista, hasta «revolucionaria», ambas autoproclamadas «auténticamente bolivarianas» como lo subrayaron D. Irwin y L.A. Buttó ${ }^{19}$.

Un elemento clave en ambas declinaciones del bolivarianismo lo es, como tuvimos la oportunidad de señalarlo, la utilización del pensamiento del Libertador por el sector castrense. Desempeñaría incluso un papel de defensa del mismo, y en primer lugar a nivel discursivo. Así sucede con el vocabulario utilizado por el chavismo para llevar a cabo campañas electorales o antes de un referéndum: la batalla de Santa Inés, 1859, en referencia a la Guerra Federal y a una de las referencias históricas de H. Chávez, Ezequiel Zamora, «General del pueblo soberano», «movilizada» por Hugo Chávez con vistas al referéndum revocatorio de 2014, dentro del «protagonismo popular» adelantado por sus seguidores, como «concepto bolivariano, democrático y eminentemente revolucionario» debidamente promovido por el PSUV ${ }^{20}$. Tal fue también la interpretación adelantada por el almirante Hernán Grúber Odreman y otros autores, en su mayoría oficiales retirados, partícipes en la «rebelión de los ángeles» (1992), a veces miembros del gobierno como fue el caso del teniente coronel de la Fuerza Aérea y teórico William Izarra, formado en EEUU, autor de En busca de la Revolución, o del capitán del Ejército Eliécer Otaiza, «héroe revolucionario» según el sitio chavista Aporrea, jefe de la Dirección de Servicios de Inteligencia Policial (DISIP) y concejal en Caracas, asesinado en circunstancias no esclarecidas. Ambos propusieron en sus escritos una «versión oficiosa del bolivarianismo» (D. Irwin, L. A. Buttó). Entre los propagandistas de este bolivarianismo de izquierda figura Heinz Dieterich, ya aludido, favorable al establecimiento de un «bloque regional de poder... única salvación nacional y popular posible para la Patria Grande de Bolívar en el siglo XXI», un liderazgo bolivariano fundador de un «nuevo proyecto latinoamericano» para enfrentar a los intereses imperialistas y neo-liberales con base a una "fusión pueblo-ejército». En la perspectiva de H. Dieterich, chavismo y bolivarianismo terminan siendo sinónimos. En ambos casos des-

19 Irwin y Buttó, 2006a. Straka, 2009: 173-202.

20 "Hace 10 años Chávez llamó a la Batalla de Santa Inés para enfrentar el Referéndum Revocatorio", PSUV, 3/6/1814, http://www.psuv.org.ve/temas/noticias/hace-10-anos-chavezllamo-a-batalla-santa-ines-para-enfrentar-referendum-revocatorio/\#.WSkt3xjpOIY. 
taca una conciencia nacionalista, republicana y latinoamericana junto al papel directivo del sector militar, que encontramos asimismo plasmado en la «Doctrina militar de la Revolución militar venezolana» así como en la legislación venezolana de seguridad, defensa y desarrollo, especialmente, en lo constitucional, legal y doctrinal, en la Ley Orgánica de la Fuerza Armada Nacional Bolivariana (LOFANB, 2008) y antes, en el Proyecto Simón Bolívar, Primer Plan Socialista de la Nación (2007) promovido por otro ideólogo de Chávez, Jorge Giordani. Para Margarita López Maya, el movimiento bolivariano que llega al poder en 1999 es «un amplio movimiento cívico-militar de naturaleza progresista y nacionalista», una «voluntad política comprometida con la reconstrucción del Estado nacional», una «estrategia ... en la lucha de los pueblos contra el capitalismo liberal», de justicia social, la «búsqueda de una democracia profunda o sustantiva con la devolución del soberano de su poder constituyente y su creciente participación en las decisiones y gestión públicas», aunque con notables "contradicciones» internas y en términos de contrapesos al poder: en pocas palabras, un «socialismo frágil» y más en un contexto de disminución de la renta petrolera ${ }^{21}$.

La crítica conceptual del siglo XX, si bien encuentra una señera y despiadada expresión en De la Patria Boba a la teología bolivariana de Luis Castro Leiva (1984) acerca de la «historicismo político bolivariano», basado en «convicciones» y «patriotismo», «falsa religión» y «teleología», se vuelve análisis historiográfico con las contribuciones de Germán Carrera Damas, tanto en El Culto a Bolívar (1989), «por y para el pueblo», como en su denuncia radical y desconstrucción intelectual del «bolivarianismo-militarismo» como «ideología de reemplazo» para el marxismo revolucionario. La fórmula e invocación de una figura simbólica, recuperada tanto por la izquierda como por la derecha, fórmula precaria de acuerdo con su autor y pese a la dificultad de ver en el chavismo una ideología en el sentido marxista de la palabra, hace hincapié tanto en el autoritarismo como en el «esponteneísmo» y la religiosidad (el «espíritu del Libertador», citando al ex guerillero Douglas Bravo y a otros integrantes de la «lucha armada» amén de gobernantes criollos), siendo la «quinta pata de la mesa» o factores estratégicos de la «conspiración» (en referencia a Pablo Medina) los militares. No carece de interés

21 Irwin y Buttó, 2006b. "Eliézer Otaiza: Atleta, pensador y soldado revolucionario", Aporrea, 29/4/2014, https://www.aporrea.org/actualidad/n249857.html. Izarra, 2001. Otaiza, 2002. Dieterich, 2004. Sobre la LOFAN(B), remitimos a los trabajos de Irwin y especialmente: Irwin y Micett, 2008 y Castillo, Irwin, Langue, 2009. Irwin, 2014. López Maya, 2008. Tomás Straka, "El socialismo pretoriano", Prodavinci (Caracas, 22/8/2016), http://prodavinci. com/2016/08/22/actualidad/el-socialismo-pretoriano-por-tomas-straka/. 
recordar que, como remedio a la «inconsistencia» ideológica de la dirigencia política en los países herederos de la Gran Colombia (Cf. las guerrillas colombianas), el bolivarianismo convertido en nuevo fundamentalismo, manipulación y «agrupación colecticia de creencias» de la historia también se aplicó en Cuba. G. Carrera Damas recuerda que la utilización del culto a Bolívar, junto con el que se le rindió a José Martí, le sirvió a Fidel Castro «para eludir la dificultad de definir el socialismo de su régimen más allá de las consignas, al igual que para encubrir su política intervencionista en diversos países de América Latina» ${ }^{22}$.

\section{LA HISTORIA OFICIAL, «LA LUNA Y EL CAUDILLO»}

La instrumentalización del pasado tal como la contempla la nueva historia oficial con visos anti-imperialistas y «bolivariana» o mejor dicho chavista descansa sin lugar a dudas en la «satanización del pasado colonial» (I. Quintero), en una «historia patria» desvirtuada y en la consiguiente reformulación del calendario conmemorativo nacional. El 12 de octubre, día del «descubrimiento de América», del «encuentro» de dos o tres mundos, «de la raza» según los países iberoamericanos se convierte en el «día de la Resistencia indígena» (decreto firmado por Chávez en 2002) y desemboca en no pocas contra-manifestaciones y derribos, «condenas» y hasta «juicios simbólicos» de elementos patrimoniales. Tal fue el caos de las estatuas asociadas a esta «leyenda negra» revisitada por la ideología (entre ellas la de Colón derribada en Caracas en octubre de 2004) pese al aparente repudio manifestado por el presidente ante semejantes actos ya que en otra oportunidad calificó la actuación de Colón de «genocida». La estatua había sido encargada a Rafael de la Cova con motivo del cuarto centenario de la llegada de Colón e instalada en 1934. Más adelante, el gobierno colocó en el hueco una nueva estatua, la del cacique Guaicaipuro, en actitud combativa ${ }^{23}$. En el mismo orden de ideas se celebran el aniversario de la rebelión popular del 27 de febrero de 1989 y el intento de golpe de Estado capitaneado por Chávez el 4 de febrero de 1992. Esta última conmemoración de una «rebelión patriótica» pasó a la posteridad mediática (el famoso «por ahora») como «una revolución de la juventud mi-

22 Castro Leiva, 1984. Carrera Damas, 1989; 2001: 45-46; 2005: 45 y 212. Straka, 2009: 61 y ss. Quintero, 2002.

23 Quintero, 2002. Daniel García Marco, “¿Dónde está la estatua de Cristóbal Colón que fue juzgada, condenada y colgada el 12 de octubre de 2004 en Caracas?”, BBC Mundo, 12/10/2016, http://www.bbc.com/mundo/noticias-america-latina-37625519. 
litar» (según el propio Chávez) o sea como otra gesta bolivariana con desfiles militares y celebraciones programadas desde el Ministerio del Poder Popular para la Cultura y encaminadas a «rememorar la historia de la Revolución Bolivariana) -24 .

El manejo simbólico de la historia nacional también desempeña un papel clave en la reescritura de la historia «bolivariana», tanto dentro como fuera de las fronteras del país habida cuenta de la propaganda oficial. Tal fue el caso de los «símbolos patrios» (escudo y bandera), modificados en 2006 de acuerdo con el credo oficial-entre otras modificaciones, el caballo blanco mira hacia la izquierda- punto de partida de una verdadera «rebelión» intelectual como lo subraya Tomás Straka, a la vez política e historiográfica de parte de profesionales de la historia, en este caso los historiadores de la Academia Nacional de la Historia en contra del «culto fundacional»: «Los símbolos patrios constituyen iconos de identificación de un Estado, y por tanto no deben ser alterados o modificados sino en circunstancias históricas trascendentales y consolidadas en la vida de un país», puntualizó el comunicado de la $\mathrm{ANH}^{25}$. Otro símbolo ampliamente mencionado en los discursos y en la propaganda de cuño alter mundialista para el «exterior», la espada de Bolívar, arma fetiche de la nación desde 1889, "camina por América» y se les regala una copia a los mandatarios amigos conforta el mito del salvador de la nación, dicho de otra forma del «Bolívar del siglo XXI $»^{26}$.

Otra notable etapa en la conformación de la historia oficial es la creación por decreto presidencial del Centro Nacional de la Historia (2007), protagonista de una «historia insurgente» como rezan su publicación en línea, oportunamente titulada Memorias de Venezuela («Hacer memoria es hacer historia» de acuerdo con su primera entrega). Esta creación propició una verdadera «guerra de las memorias», fundada en la insólita confusión entre la(s) memoria (s) que tienden a dividir de acuerdo con el análisis de P. Ricœur y la historia, instrumento de conocimiento cuyo fundamento epistemológico tiende, en cambio, a reunir. La reescritura de la historia se centra en efecto en una revisión maniquea del culto a Bolívar. Entre enero de 2007 y enero de 2008 se crea en efecto una comisión presidencial encargada de comprobar las

24 Juan Paullier, "Chávez conmemora los 20 años de un golpe fallido", BBC Mundo, 3/2/2012, http://www.bbc.com/mundo/noticias/2012/02/120202_venezuela_aniversario_golpe_ estado_4_febrero_jp.shtml. Langue, 2010.

25 Gaceta Oficial, 38.394, Caracas 9/5/2006, http://www.inpsasel.gob.ve/moo_doc/gaceta_bandera.pdf. Straka, 2009: 21 y ss. Langue, 2013.

26 "La Academia Nacional de la Historia y los símbolos patrios", comunicado del 9/2/2006: http://anhvenezuela.org.ve/anhnva//sites/default/files/1/ANH_comunicado_utiliacion_simbolos_._09022006.pdf. 
causas de la muerte del héroe, asesinado por oligarcas venezolanos y colombianos (sic), «tradiciones inventadas» (T. Straka) ampliamente retomadas por los medios chavistas prontos a denunciar conspiraciones del «imperio» en contra del Bolívar del siglo XX/XXI y por lo tanto en contra de la «segunda Independencia», $\mathrm{y}$ más en el contexto de las conmemoraciones del Bicentenario de la Independencia.

Otro momento clave del enfrentamiento entre turiferarios del régimen e historiadores críticos lo fue la transferencia de los archivos del Libertador Simón Bolívar y del Precursor Francisco de Miranda desde la Academia Nacional de la Historia al Archivo Nacional de la Nación (10/6/2010). La exhumación de los restos de Bolívar en julio de 2010 consagra de cierta forma la identificación entre el Bolívar de ayer y el Bolívar del tiempo presente, iniciativa que coincidió con el natalicio de Bolívar y permitió validar la interpretación del asesinato del Libertador (sic). Con el episodio del retrato de Bolívar, encargado por H. Chávez, culminó la reescritura de la historia bolivariana en su vertiente visual: en el retrato digitalizado, obra de «científicos», presentado en un acto oficial en 2012, el aristócrata blanco, criollo, mantuano, se transfiguró en un mestizo de tez oscura y pelo «achicharrao», que poco tiene que ver con las pinturas de la época, la imagen familiar o sea el modelo retratado por José Gil de Castro en 1826 y la amplia iconografía al respecto, sustentada incluso en las tradiciones visuales de las élites coloniales. Esta reescritura visual de la historia viene a reforzar la historia oficial tal como la concibe la Revolución: se hace hincapié en los aspectos más «revolucionarios» de Bolívar -hasta afirmar que libertó a los esclavos (sic)- que algunos apologetas no habían dudado ya en presentar no como un aristócrata criollo blanco (un mantuano) sino como un zambo o sea como un mestizo de tez oscura, tal como aparecería en el retrato digital de 2012, en un momento en que la ofensiva de la historia oficial alcanza un paroxismo insólito en la historia nacional ${ }^{27}$.

27 Ricœur, 2000. Decreto presidencial del 12/4/2010, http://anhvenezuela.org/boletin. php? cod=25. Straka, 2009: 173 y ss. Langue, 2015. Maye Primera, “Chávez 'resucita' a Bolívar para salvarse. El presidente venezolano ordena la exhumación de los restos del Libertador para tapar los problemas presentes", El Pais, 16/8/2010, http://internacional.elpais.com/ internacional/2010/07/16/actualidad/1279231207_850215.html. Elías Pino Iturrieta, “El nuevo rostro de Bolívar?", El Universal (Caracas, 29/7/2012) http://www.eluniversal.com/opinion/120729/el-nuevo-rostro-de-bolivar. J. Molina, "El disputado rostro del Libertador", El País, 1/8/2012, http://cultura.elpais.com/cultura/2012/08/01/actualidad/1343837626_628498. html. Engel, 2016. Pino Iturrrieta, 2007: 87-88 y 93-105. "Chávez revela la foto digital del rostro de El Libertador Simón Bolívar", Telesur (canal officiel diffusant sur tout le continent latino-américain), 24/7/2012, http://www.telesurtv.net/articulos/2012/07/24/chavez-revela-lafoto-digital-del-libertador-simon-bolivar-3235.html. 
La movilización ideológica tal como se delineó durante los años de gobierno de H. Chávez, la justificación del «mal» ante el «mal» encarnado -Estados Unidos y sur correlato interno, la oposición-, la denuncia del «enemigo» (interno y externo) hacen que el «pensamiento mágico» muy a menudo vinculado con recientes expresiones del bolivarianismo y fundado en elementos dispares que incluyen las secuelas del colonialismo y su visión fatalista del mundo, no se exime de recurrir a las emociones en su vertiente negativa, especialmente al resentimiento, instrumentalizado hasta el extremo por la Revolución bolivariana. «El Bolívar de Chávez genera odios y divide a la sociedad», puntualizó Elías Pino. A esto le podríamos añadir que el bolivarianismo de hoy, con su instrumentalización del pasado nacional y la desvalorización de quienes no apoyan el régimen «revolucionario», corre parejas con el manejo del resentimiento que no resulta sólo de un "pasado que no pasa» y de determinados usos políticos y sociales del mismo, sino que se construye junto a la verdad ejemplificada como soporte de la memoria, como reza la historia oficial. La instrumentalización de las emociones y de su inversión con fines propagandísticas se inserta de esta forma en una «cultura de la guerra», en el maniqueísmo vencedores/vencidos, la denuncia del (neoimperialismo) y la consiguiente «victimización» de los «buenos». Una aproximación en términos de historia cultural de la guerra o de forma más general de historia de los conflictos, pone de relieve el hecho de que la historia oficial no hace sino legitimar, gracias a la confusión historia/memoria explícitamente introducida, y a la innovación de una palabra sagrada ${ }^{28}$.

Al igual que los «tigres de papel» de la revolución maoísta, expresión forjada por Mao Zedong para designar a sus enemigos de poca monta y especialmente al imperialismo norteamericano (en una entrevista de 1956), el bolivarianismo del siglo XXI desemboca a la vez en una memoria negativa y en una absolución: una memoria «negativa» si consideramos en efecto el fracaso final de Bolívar en cuanto hombre de su tiempo y el resquebrajamiento del proyecto bolivariano exclusivista de Hugo Chávez (uno estaba a favor de la Revolución, o por defecto, en su contra) así como sus propuestas ideológicas a escala del continente. Una absolución si recordamos la conmemoración por $\mathrm{H}$. Chávez a los veinte años del fallido golpe del 4 de febrero de 1992 (la «rebelión de los ángeles», a raíz de la cual estuvo preso durante dos años antes de ser liberado, "sobreseído» por el presidente Rafael Caldera),

28 Langue, 2016a; 2016b. Entrevista a Elías Pino Iturrieta: "El Bolívar de Chávez genera odios y divide a la sociedad", El Universal, 29/7/2012, http://www.eluniversal.com/nacionaly-politica/120729/el-bolivar-de-chavez-genera-odios-y-divide-a-la-sociedad-imp. Erner, 2006. Ascensio, 2012. 
condenado sin embargo por quien fuera en el siglo XXI su mentor, Fidel Castro: «El 4 de febrero no fue un golpe de Estado, fue una revolución de la juventud militar. A mí que me condenen los que quieran condenarme. Qué me importa. La historia me absolverá» ${ }^{29}$.

Esta frase, pronunciada por Fidel Castro con motivo de su juicio (16/10/1953) consecutivo al ataque del cuartel Moncada (26 de julio de 1953) significó la incorporación en el imaginario nacional e internacional de la Revolución y de las izquierdas progresistas de la Revolución Cubana, que pondría fin a la dictadura de Fulgencia Batista luego de varios años de guerrilla y de exilio en los países vecinos. La segunda parte de la historia bien es conocida: eliminación de los compañeros de lucha y de las fuerzas progresistas de la isla desde los años sesenta (cf. caso Huber Matos), imposición de un universo represivo y carcelario que poco tenía que ver con los «ideales» de la Revolución. Este proceso se benefició en gran medida de la ceguera «solidaria» de las izquierdas occidentales y especialmente de sus intelectuales. El libro de J. Verdés-Leroux, La lune et le caudillo (La luna y el caudillo, 1989) despertó en este sentido pocos ecos. Contrarrestado en el continente y más allá a partir de 1969, el castrismo encontró con Hugo Chávez un nuevo aliento, tanto desde el punto de vista económico y financiero -después de la caída no tan simbólica del Muro de Berlín- como a nivel ideológico y político, que muy pocos especialistas de ambos países han intentado o querido subrayar. Las «correspondencias» entre ambos procesos resultan sin embargo notables a partir del año 2004: modalidades de la «radicalización», discursividad de las ofensivas «revolucionarias» y propagandísticas a través de la historia oficial de turno, dimensión militar y hasta pretoriana, comités de defensa de la Revolución («círculos bolivarianos»), eliminación de los «críticos» u opositores (el general Raúl Baduel en el caso de Venezuela), presencia de los «consejeros»y de los cuerpos de seguridad cubanos en Venezuela, y, finalmente, represión, más evidente durante el mandato del sucesor de Chávez, y desaparición de éste en La Habana en diciembre de 2012 y no en Venezuela de acuerdo con la fecha oficial de su muerte (5 de marzo de 2013). En cuanto a la historia oficial, recoge determinados mitos nacionales o continentales e instrumentaliza el pasado (representación visual de los héroes, olvido o rechazo a determinados períodos de la historia nacional, museos de la Revolución). Ambos «comandantes» se encuentran además valorados por una extrema izquierda europea de cuño autoritario y populista, aunque pretendida-

29 Rousso, 2016: 229 y ss. Juan Paullier, “Chávez conmemora los 20 años de un golpe fallido", BBC Mundo, 3/2/2012, http://www.bbc.com/mundo/noticias/2012/02/120202_venezuela_aniversario_golpe_estado_4_febrero_jp.shtml. 
mente «insumisa». El proyecto bolivariano hasta se «invitó» a través del ALBA en la campaña electoral para las elecciones presidenciales galas. En Cuba, los mecanismos de la reescritura de la historia oficial fueron similares, como lo subrayó Rafael Rojas en la «máquina del olvido»: la ideología del Estado, la Revolución como fe inquebrantable, la lucha contra el «enemigo» externo o interno, tal como el bolivarianismo chavista las llegó a difundir. Los «regímenes emocionales»-y no sólo historiográficos- también presentan fuertes similitudes al valorar una violencia instalada en las prácticas políticas y no solamente guerreras, e, in fine, «políticas de la enemistad» ${ }^{30}$. Quizás radique la mayor diferencia entre ambas revoluciones en el paradójico devenir de sus finados líderes: si bien en los primeros meses de 2017 fueron derribadas y destruidas no pocas estatuas de H. Chávez, no sucedió así con los recuerdos de «Fidel», quien tuvo la inmensa sabiduría de nunca mandar a edificar estatuas en su honor -a diferencia de casi todos los dictadores del planeta-. En cambio, sí cuidó la escritura de una historia oficial asentada tanto en el relato histórico propiamente dicho como en testimonios visuales (sobre todo fotografías). Posibilitó de esta manera la conformación de un imaginario visual difícil de borrar no sólo del tiempo presente sino también de unas memorias mundializadas ${ }^{31}$.

\section{BiBLIOGRAFÍA}

Alarico Gómez, Carlos, Marcos Pérez Jiménez. El último dictador, Caracas, Los Libros de El Nacional, 2007.

Ascensio, Michaelle, De que vuelan, vuelan. Imaginarios religiosos venezolanos, Caracas, Editorial Alfa, 2012.

Blanco Muñoz, Agustín, Habla el Comandante. Venezuela del 04F-92 al 06-D-98, Caracas, UCV-Cátedra Pío Tamayo, 1998.

30 Vinogradoff, 2016. Rojas, 2011; 2015; 2017. Entrevista del Nuevo Herald (30/5/2015), "Rafael Rojas y la Revolución Cubana: otro punto de vista", http://www.elnuevoherald.com/ vivir-mejor/artes-letras/article22349526.html. Mbembe, 2016.

31 "Un vídeo de la destrucción de una estatua de Chávez se hace viral en Venezuela. La efigie fue destruida durante una marcha estudiantil contra el presidente Maduro", El País, 6/5/2017 http://internacional.elpais.com/internacional/2017/05/06/actualidad/1494071642 467241.html. Frédérique Langue, "Fidel Castro stratège de l'image ou la mise en scène de la Révolution", Carnet de l'Institut d'Histoire du Temps Présent, 19/1/2017, https://ihtp.hypotheses.org/2457\#more-2457. 
Blanco Muñoz, Agustín, Del proyecto al proceso. Habla Joel Acosta Chirinos, Caracas, UCV-Cátedra Pío Tamayo, 2006.

Caballero, Manuel, Rómulo Betancourt, político de nación, Caracas, Alfadil/FCE, 2004.

Carrera Damas, Germán, El Culto a Bolivar, Caracas, Grijalbo, 1989.

Carrera Damas, Germán, Alternativas ideológicas en América Latina contemporánea (El caso de Venezuela: el bolivarianismo-militarismo), Gainesville, UCV-Escuela de Historia/University of Florida-Center for Latin American Studies, 2001.

Carrera Damas, Germán, El Bolivarianismo-Militarismo. Una ideología de reemplazo, Caracas, Ala de Cuervo, 2005.

Castillo, Hernán, Militares y Control Civil en Venezuela, Caracas, USB-Universidad de los Andes, 2013.

Castillo, Hernán, Irwin, Domingo y Langue, Frédérique, Problemas Militares Venezolanos. FANB y Democracia en los inicios del siglo XXI, Caracas, Universidad Pedagógica Experimental Libertador y Universidad Católica Andrés Bello, 2009.

Castro Leiva, Luis, De la Patria Boba a la Teología Bolivariana, Caracas, Monte Ávila Editores, 1984.

Ceresole, Norberto, Caudillo, ejército, pueblo. La Venezuela del Comandante Chávez, Madrid, Estudios Hispano-Arabes, 2000.

Coppedge, Michael, Strong Parties and Lame Ducks: Presidential Partyarchy and Factionalism in Venezuela, Stanford, Stanford University Press, 1994.

Coppedge, Michael, "Explaining Democratic Deterioration in Venezuela Through Nested Inference", Frances Hagopian and Scott Mainwaring (eds.), The Third Wave of Democratization in Latin America, Cambridge/New York, Cambridge University Press, 2005: 289-316.

Dávila, Luis Ricardo, El imaginario político venezuelano: ensayo sobre le Trienio octubrista, 1945-1948, Caracas, Alfadil/Trópicos, 1992.

Dieterich, Heinz, Hugo Chávez: el destino superior de los pueblos latinoamericanos: conversaciones con Heinz Dieterich, Caracas, Alcaldía de Caracas, 2004.

Engel, Emily A., "Simón Bolívar's Itinerant Portraits", Maureen G. Shanahan and Ana María Reyes, Simón Bolívar. Travels \& Transformation of a Cultural Icon, Gainesville, University Press of Florida, 2016: 27-47.

Erner, Guillaume, La société des victimes, París, La Découverte, 2006.

Garrido, Alberto, La historia secreta de la Revolución Bolivariana, Mérida, Editorial Venezolana, 2000.

Irwin, Domingo, "El Libertador y las relaciones civiles-militares: una síntesis interpretativa", Tiempo y Espacio, 34 (Caracas, 2000a): 89-148. 
Irwin, Domingo, Relaciones civiles-militares en el siglo XX, Caracas, El Centauro Ediciones, 2000b.

Irwin, Domingo, "Una visión histórica de conjunto sobre las relaciones políticas entre los civiles y los militares venezolanos en el siglo XX", Research and Education, in Defense and Security Studies Seminars, Washington, CHDS-NDU, mayo de 2001, http://www.ndu.edu/.

Irwin, Domingo, "Reseña de una línea de investigación en el Centro de Investigaciones Históricas Mario Briceño Iragorry”, Tiempo y Espacio, 41 (Caracas, 2014): 47-61.

Irwin, Domingo y Buttó, Luis Alberto, "The Literature behind Venezuelan Bolivarian", Military Review (Fort Leavenworth, Kansas, March-April 2006a): 82-87.

Irwin, Domingo y Buttó, Luis Alberto, “«Bolivarianismos» y Fuerza Armada en Venezuela”, Nuevo Mundo Mundos Nuevos, 6 (París, 2006b), http://nuevomundo. revues.org/1320.

Irwin, Domingo y Langue, Frédérique, "Militares y democracia ¿El dilema de la Venezuela de principios del siglo XXI?", Revista de Indias, 231 (Madrid, 2004): 549-559, http://revistadeindias.revistas.csic.es/index.php/revistadeindias/article/ view/426/494.

Irwin, Domingo y Micett, Ingrid, Caudillos, militares y poder. Una historia del pretorianismo en Venezuela, Caracas, UCA-UPEL, 2008.

Izarra, William, En Busca de la Revolución, Caracas, Producciones Karol, 2001.

Langue, Frédérique, Hugo Chávez et le Venezuela. Une action politique au pays de Bolivar, París, L'Harmattan, 2002.

Langue, Frédérique, "La Independencia de Venezuela. Una historia mitificada y un paradigma heroico", Anuario de Estudios Americanos, 66/2 (Sevilla, 2009): 245276, http://estudiosamericanos.revistas.csic.es/index.php/estudiosamericanos/issue/view/22.

Langue, Frédérique, "De panteones cívicos e imaginarios políticos. Los usos del pasado en la Revolución bolivariana", Francesca Ramos Pismataro, Carlos A. Romero y Hugo Eduardo Ramirez Arcos (dir.), Hugo Chávez: una década en el Poder, Bogotá, Universidad del Rosario/Centro de Estudios Políticos e Internacionales/Observatorio de Venezuela, 2010: 761-781.

Langue, Frédérique, “«Levántate Simón, que no es tiempo de morir». Reinvención del Libertador e historia oficial en Venezuela", Araucaria Revista Iberoamericana de Filosofía, Política y Humanidades, 25 (Sevilla, 2011): 26-45, http://www-en. us.es/araucaria/nro25/nro25.htm.

Langue, Frédérique, "Usos del pasado y guerra de las memorias en la Venezuela de la 'Segunda Independencia'”, Polis, 34 (Santiago de Chile, 2013), http://polis. revues.org/8953. 
Langue, Frédérique, “L'Empire et la Révolution ou Bolivar et son double”, Caravelle, 104 (Toulouse, 2015): 13-29, http://caravelle.revues.org/1537.

Langue, Frédérique, "Entre el clavel y la espada. Por una historia cultural de las relaciones civiles-militares (de Europa a Chile, Argentina, Venezuela)" Tiempo y Espacio, 65 (Caracas, 2016a): 135-153, http://www.scielo.org.ve/scielo.php?scrip$t=s c i$ arttext\&pid=S1315-94962016000100009\&lng=es\&nrm=is\&tlng=es.

Langue, Frédérique, "Un pasado que no pasa: emociones y salvación en la Venezuela del tiempo presente", Boletín Americanista, 72 (Barcelona, 2016b): 237-256, http://revistes.ub.edu/index.php/BoletinAmericanista/article/view/16052.

López Maya, Margarita, "Venezuela: Hugo Chávez y el bolivarianismo", Revista Venezolana de Economía y Ciencias Sociales, 14/3 (Caracas, 2008): 5-82.

Mbembe, Achille, Politiques de l'inimitié, París, La Découverte, 2016.

Otaiza, Eliécer, Retórica Bolivariana. Primer Ensayo Político. La Defensa, Caracas, Imprenta Negrín Central, 2002.

Pino Iturrieta, Elías, El divino Bolivar. Ensayo sobre una religión republicana, Madrid, Catarata, 2003.

Pino Iturrrieta, Elías, Nada sino un hombre. Los orígenes del personalismo en Venezuela, Caracas, Editorial Alfa, 2007.

Quintero, Inés, "Nación y construcción discursiva. Bolívar de izquierda, Bolívar de derecha", Historia Caribe, II/7 (Barranquilla, 2002), http://www.redalyc.org/ pdf/937/93720706.pdf.

Quintero, Inés, "Las «Historias Patrias»: alcances, límites y recurrencias", Rogelio Altez (ed.), Las independencias hispanoamericanas: un debate para siempre, Bucaramanga, Universidad de Santander/Colección Bicentenario, 2012: 91-123.

Ramos Jiménez, Alfredo, El experimento bolivariano. Liderazgo, partidos y elecciones, Mérida, Universidad de los Andres/CIPCOM, 2009.

Ricœur, Paul, La memoria, la historia, el olvido, México, FCE, 2000.

Rojas, Rafael, La máquina del olvido. Mito historia y poder en Cuba, México, Taurus, 2011.

Rojas, Rafael, Historia mínima de la Revolución Cubana, México, El Colegio de Mexico, 2015.

Rojas, Rafael, "Comunistas en democracia. El orden constitucional de 1940 en Cuba y la estrategia electoral del comunismo”, Conserveries mémorielles, 20 (París, 2017) http://cm.revues.org/2661.

Rousso, Henry, Face au passé, París, Belin, 2016.

Straka, Tomás, La épica del desencanto, Caracas, Editorial Alfa, 2009. 
Uzcátegui, Luis José, Chávez mago de las emociones. Análisis psicosocial de un fenómeno político, Caracas, Ed. Lithopolar, 1999.

Vinogradoff, Ludmila, El ocaso de Chávez, Caracas, 2016.

Zago, Angela, La rebelión de los ángeles. Reportaje. Los documentos del movimiento, Caracas, Warp ediciones, 1998.

Fecha de recepción: 3 de marzo de 2017.

Fecha de aceptación: 19 de junio de 2017.

\section{Bolivarianisms as paper tigers}

This essay reconsiders not so much the forms taken by the cult of Bolivar within its official expression as the way it became a theory for thought and political action in the long term. We will consider civil-military relations - the cornerstone of Hugo Chávez'Bolivarian Projectthe representations linked to Bolivarian ideology both inside and outside the academic world, and finally the recent and biased memorial rewriting of the present day in Venezuela.

KeY wORDS: Venezuela; Bolivarianism; memory; Hugo Chávez; praetorianism; revolution; independence. 